Neurosurg Focus 6 (4):Article 2, 1999

\title{
Neuroendoscopic third ventriculostomy
}

Neil Buxton, F.R.C.S.(Ed)

Department of Neurosurgery, University Hospital, Nottingham, United Kingdom

Neuroendoscopic third ventriculostomy is becoming increasingly popular as the primary mode of therapy for patients with noncommunicating hydrocephalus. In this article the author reviews the procedure and its indications, and highlights its complications. It can, without doubt, be recommended as the first line treatment for hydrocephalus and also in cases in which shunt malfunction or infection occurs.

Key Words * neuroendoscopy * neuroendoscopic third ventriculostomy * third ventriculostomy * hydrocephalus

Neuroendoscopy has enjoyed a renaissance over the last few years, especially in the treatment of hydrocephalus. In this review focus will be placed on the treatment of hydrocephalus by neuroendoscopic third ventriculostomy (NTV), which is the most commonly used neuroendoscopic technique for hydrocephalus.

\section{HISTORICAL PERSPECTIVE}

Endoscopic procedures in neurosurgery are by no means new. The first cases were those reported by Lespinasse in 1910; he performed choroid plexus ablation by using a rigid cystoscope in two children with hydrocephalus.[9] Third ventriculostomy, attained by using a cytoscope, was first reported by Mixter in 1923.[22] Putnam[25] performed endoscopic choroid plexectomy, and Scarff,[27] performed third ventriculostomy despite the fact that open procedures were being advocated by Dandy.[8] Nevertheless, Scarff prevailed in his use of third ventriculostomy and published his results of third ventriculostomy in the 1960s[28,29] and choroid plexus ablation in 1970.[30]

The evolvement of better optics enabled the development of more useful endoscopes. Griffith adopted this technology and performed choroid plexectomies via a rigid endoscope for which he obtained a success rate of 49\%.[11] During this time Vries developed an endoscopic technique for third ventriculostomy for the treatment of patients with hydrocephalus.[38] The use of endoscopes to treat intraventricular cysts and cerebellopontine angle conditions was also proposed.[11]

Since the beginning of the 1990s endoscopic neurosurgical procedures have soared in popularity because they are truly minimally invasive in most instances. Their most useful application remains in the treatment of hydrocephalus, most commonly by third ventriculostomy. 


\section{NEUROENDOSCOPIC INSTRUMENTS}

There are essentially two schoolsof thought regarding the usage of neuroendoscopes: those who use flexible and those who use rigid endoscopes. Both types of endoscope have advantages and disadvantages. Today's instruments are purpose built, and the fundamental differences between them are small.

Optically rigid endoscopes have always been better than those that are flexible, but flexible endoscopes have been improved. Flexible endoscopes are more expensive than rigid endoscopes because of the fiber optic technology used. The flexible endoscope is more versatile than the rigid endoscope because it allows access to almost the whole of the ventricular system (although it is easy to become disorientated), whereas the rigid endoscope only provides safe access to structures along its path of insertion. Rigid endoscopes tend to be of greater diameter than flexible endoscopes, which allows for larger more robust instrumentation. However, the standard instrumentation available for both types has improved markedly.

Once an endoscope has been selected, other challenges must be met. Not only must the surgeon be trained to use it but the operating room staff need to be trained in the care of the instruments as well as the ancillary equipment used with them.

The specific required instrumentation is largely dependent on which procedure is being undertaken. For example, to perform an NTV one must chose between using: rigid or flexible endoscopes; stereotactic image-guided, intraoperative ultrasound-guided or essentially free-hand systems; and the use of laser, diathermy, scissors, or a balloon to create the ventriculostomy. Similar considerations have to be made for other neuroendoscopic procedures.

Good irrigation is essential to the success of all neuroendoscopic procedures, as is the use of good-quality camera and video systems.

\section{IMAGING ASSESSMENT}

Preoperative imaging is essential. The quality of magnetic resonance imaging exceeds computerized tomography scanning in anatomical detail, and it is this detail that is required in the treatment of hydrocephalus by neuroendoscopic techniques. A MR image can demonstrate membranes, cerebrospinal fluid (CSF) flow voids, and the position of blood vessels.[17] Evaluation of imaging studies will also indicate whether the NTV technique can be used. Very small ventricles and small foramina of Monro, for instance, are difficult to place an endoscope in, and preoperative imaging studies would indicate this.

Postoperative assessment of ventriculostomy patency and CSF flow is also possible.[18,19] In infants with open anterior fontanelles ultrasonography can be performed, and color flow Doppler ultrasound elegantly demonstrates flow through the ventriculostomy in successful cases.[35] The postoperative size of the ventricles appears to have no correlation with outcome because some cases with smaller ventricles can fail, whereas some with larger ones can actually be successful.[3]

\section{NEUROENDOSCOPIC THIRD VENTRICULOSTOMY}

Neuroendoscopic third ventriculostomy has become the most common neuroendoscopic procedure. Although it is an internal CSF-diversionary procedure best suited to noncommunicating hydrocephalus, it has had some unexplained success in communicating hydrocephalus.[3,4] 
The technique used in our surgical unit involves drilling a right-sided, precoronal burr hole in the pupillary line, insertion of a peel-away trocar into the lateral ventricle; insertion of a flexible endoscope and passage of the endoscope through the foramen of Monro; identification of the anatomical landmarks on the floor of the third ventricle; production of the ventriculostomy by using diathermy; enlargement of the hole by using a balloon catheter if necessary; and passage of the endoscope through the ventriculostomy to ensure it is of adequate size and also to identify any second membranes that might lead to technical failure of the NTV.

The most important considerations are the proper position of the precoronal burr hole so that direct-line access to the third ventricle is enabled; passing the endoscope through the foramen of Monro without damaging the thalamostriate vein, fornix, or choroid plexus; and selection of the position on the floor of the third ventricle for the ventriculostomy.

Instead of it performing a virtually free-hand procedure, some authors use stereotactically guided NTV,[14] frameless stereotaxy,[10] or ultrasonographic guidance.[26] The more rigidly the endoscope is held the less flexible it is. Concerns regarding stereotactic procedures include brain shift once the ventricles are entered, thereby rendering the coordinates and calculated trajectories inaccurate. In the light of these drawbacks, the advantages of ultrasonography or realtime neuronavigational techniques are obvious.

The anatomical landmarks on the floor of the third ventricle are identified. Preoperative imaging studies should be used to guide the surgeon to the location of the basilar artery (BA) in relation to the mammillary bodies and the floor itself. Anteriorly, the area vasculosum, indicating the origin of the pituitary infundibulum, is seen as are the mammillary bodies posteriorly. In using the flexible endoscope, the origin of the sylvian aqueduct can also be seen, and in the case of aqueduct stenosis, its closure can be confirmed. The third ventriculostomy is then made anterior to the mammillary bodies, as close to the clivus as possible, posterior to the area vasculosum, avoiding the basilar artery. In many cases of established hydrocephalus the floor will be a thin membrane through which structures are visible. In cases of postmeningitic hydrocephalus or dysmorphic brains, the structures of the floor may not be easily recognized. The use of microvascular Doppler probes enables the artery to be identified and, therefore, not damaged.(Schmidt [31] and Vloeberghs, et al.[37]).

The third ventriculostomy itself is achieved by various techniques. Pushing the tip of a rigid endoscope through,[16] diathermy,[3] laser,[36] balloon-tipped catheters,[32] or saline torch[13] have all been reported.

Passing the endoscope through the ventriculostomy ensures that it is large enough and that any second membranes, such as Lilliequist's membrane, can be seen and opened to avoid technical failure.[5] In cases in which the second membrane was not initially recognized it can be dealt with at a second NTV.

To confirm that flow is successfully achieved the endoscope is withdrawn a few millimeters, irrigation is ceased, and the frondlike edges of the ventriculostomy are observed wafting back and forth like plants in the sea.[3]

In our unit we have analyzed a series of patients in whom endoscopic procedures were performed. Of special interest has been the fate of NTV in young patients because of the myriad of problems caused by shunts in this age group; these results have been previously published.[3,4]

In our unselected series of patients of various ages presenting with hydrocephalus of mixed causes, the 
success rate of NTV was $57 \%$ overall (N Buxton, unpublished data), whereas others have reported a success rate of $61 \%$.[15] Of those patients with noncommunicating hydrocephalus alone (secondary to aqueductal stenosis or tumor), treatment failed in six of 31 patients; thus, an $81 \%$ success rate was achieved (N Buxton, unpublished data). When the patients with communicating hydrocephalus are included, the success rate decreases. In one series published by this unit,[4] for example, in $81 \%$ of patients with communicating hydrocephalus treatment failed. However, why the therapy should succeed in any patients with communicating hydrocephalus remains unexplained.

The advantages of being able to perform this procedure are that the patient is relieved of the burden of having a shunt and therefore its associated morbidity and mortality.[23] There are also economical advantages associated with NTV.[2]

Complications of NTV are increasingly being reported, some of which are associated with damage to blood vessels during the creation of the ventriculostomy, and they include BA perforation that produces a pseudoaneurysm,[1,21] fatal subarachnoid hemorrhage,[32] and traumatic pericallosal aneurysm.[7] Other complications include near-fatal cardiac arrest,[12] infection, epilepsy, and intraoperative hemorrhage.[24] Complication rates have been reported to range between 15 to $20 \%$ of cases in which NTV is performed.[3,34] Experience with this technique will lead to fewer complications.

Follow-up review of these patients indicates that failure can be expected to occur between 1.2 and 1.36 months (range 0-4 months),[3,4] and that after this time, long-term success can be expected.[6]

\section{NEUROENDOSCOPIC THIRD VENTRICULOSTOMY IN PATIENTS WITH SHUNTS}

This technique is performed in exactly the same way as in primary NTV for hydrocephalus, that is, in those patients who have not undergone previous treatment for hydrocephalus.

In patients in whom shunts have been previously placed, and who present with malfunction or infection, NTV has been reported to have a 76.7 to $77 \%$ success rate. $[6,20]$ In these patients the shunt is removed or tied off after the procedure to encourage its patency. The French series [6] is spread over a longer time-frame than that of ours,[20] and those authors used different techniques to achieve the same end. Both series demonstrate that in anatomically suitable patients NTV procedures can be successful, regardless of the original cause of hydrocephalus, thus relieving patients of the burden of a shunt.

\section{CONCLUSIONS}

Neuroendoscopic third ventriculostomy is undoubtedly of value in the treatment of hydrocephalus. It is best suited to cases of noncommunicating hydrocephalus such as in aqueductal stenosis or secondary to tumor, and good success rates are achieved in myelomeningocele patients.[33] Although the treatment of communicating hydrocephalus by NTV theoretically should not work, in some patients it appears to do so. In some patients in whom shunts have been placed for communicating hydrocephalus, such as in posthemorrhagic hydrocephalus, NTV performed subsequent to shunt failure is successful. One can only assume that this is due to subsequent maturation of undamaged arachnoid granulations, coupled with closure of the sutures, allowing the build up of a sufficiently large pressure gradient to create CSF egress.

As a tool for the treatment of noncommunicating hydrocephalus NTV is to be recommended as the primary therapy as well as in those who have undergone previous shunt placement. However, because the complications can be severe, it is not a technique for the occasional endoscopist. 


\section{References}

1. Abtin K, Thompson BG, Walker ML: Basilar artery perforation as a complication of endoscopic III ventriculostomy. Childs Nerv Syst 14:412, 1998 (Abstract)

2. Barlow P, Ching HS: An economic argument in favour of endoscopic third ventriculostomy as a treatment for obstructive hydrocephalus. Minim Invasive Neurosurg 40:37-39, 1997

3. Buxton N, Macarthur D, Mallucci C, et al: Neuroendoscopic third ventriculostomy in patients less than 1 year old. Pediatr Neurosurg 29:73-76, 1998

4. Buxton N, Macarthur D, Mallucci C, et al: Neuroendoscopy in the premature population. Childs Nerv Syst 14:649-652, 1998

5. Buxton N, Vloeberghs M, Punt J: Liliequist's membrane in minimally invasive endoscopic neurosurgery. Clin Anat 11:187-190, 1998

6. Cinalli G, Salazar C, Mallucci C, et al: The role of endoscopic third ventriculostomy in the management of shunt malfunction. Neurosurgery 43:1323-1329, 1998

7. Cohen AR: Endoscopic ventricular surgery. Pediatr Neurosurg 19:127-134, 1993

8. Dandy WE: Cerebral ventriculoscopy. Johns Hopkins Hosp Bull 33:189, 1922

9. Davis L: Principles of Neurological Surgery, ed 2. Philadelphia: Lea \& Febiger, 1942

10. Golfinos JG, Fitzpatrick BC, Smith LR, et al: Clinical use of a frameless stereotactic arm: results of 325 cases. J Neurosurg 83:197-205, 1995

11. Griffith HB: Endoneurosurgery: endoscopic intracranial surgery. Adv Tech Stand Neurosurg 14:2-24, 1986

12. Handler MH, Abbott R, Lee M: A near-fatal complication of endoscopic third ventriculostomy: case report. Neurosurgery 35:525-528, 1994

13. Heilma CB, Cohen AR: Endoscopic ventricular fenestration using a "saline torch." J Neurosurg 74:224-229, 1991

14. Hellwig D, Bauer BL: Endoscopic procedures in stereotactic neurosurgery. Acta Neurochir Suppl 52:30-32, 1991

15. Jones RFC, Kwok BCT, Stening WA, et al: Neuroendoscopic third ventriculostomy. A practical alternative to extracranial shunts in non-communicating hydrocephalus. Acta Neurochir Suppl 61:79-83, 1994

16. Jones RFC, Stening WA, Brydon M: Endoscopic third ventriculostomy. Neurosurgery 26:86-92, 1990

17. Laitt R, Mallucci CL, Jaspan T, et al: Constructive interference in steady-state 3D Fourier-transform MRI in the management of hydrocephalus and third ventriculostomy. Neuroradiology 41: 117-123, 1999 
18. Lev S, Bhadelai RA, Estin D, et al: Functional analysis of third ventriculostomy patency with phase-contrast MRI velocity measurements. Neuroradiology 39:175-179, 1997

19. Maeder P, Gudinchet F, Meuli R, et al: Dynamic MRI of cerebrospinal fluid flow in endoscopic percutaneous ventriculostomy. Br J Neurosurg 12:18-22, 1998

20. Mallucci CL, Vloeberghs M, Punt JA: Neuroendoscopic III ventriculostomy: the first-line treatment for blocked ventriculo-peritoneal shunts? Childs Nerv Syst 13:498, 1997 (Abstract)

21. McLaughlin MR, Wahlig JB, Kaufmann AM, et al: Traumatic basilar aneurysm after endoscopic third ventriculostomy: case report. Neurosurgery 41:1400-1404, 1997

22. Mixter WJ: Ventriculostomy and puncture of the floor of the third ventricle. Boston Med Surg J 188:277-278, 1923

23. Pople I: Management of shunt complications, in Palmer JD (ed): Neurosurgery 96: Manual of Neurosurgery. New York: Churchill Livingstone, 1996, pp 590-592

24. Punt J, Vloeberghs M: Endoscopy in neurosurgery. Min Invasive Ther Allied Technol 7:159-170, 1998

25. Putnam TJ: Treatment of hydrocephalus by endoscopic coagulation of the choroid plexus. N Engl J Med 210:1373-1376, 1934

26. Rieger A, Rainov NG, Sanchin L, et al: Ultrasound guided endoscopic fenestration of the third ventricular floor for non-communicating hydrocephalus. Minim Invasive Neurosurg 39:17-20, 1996

27. Scarff JE: Endoscopic treatment of hydrocephalus. Description of a ventriculoscope and preliminary report of cases. Arch Neurol Psychiatry 35:853-861, 1936

28. Scarff JE: Evaluation of treatment of hydrocephalus. Results of third ventriculostomy and endoscopic cauterization of choroid plexuses compared with mechanical shunts. Arch Neurol 14:382-391, 1966

29. Scarff JE: Treatment of hydrocephalus: an historical and critical review of methods and results. $\mathbf{J}$ Neurol Neurosurg Psychiatry 26:1-26, 1963

30. Scarff JE: The treatment of nonobstructive (communicating) hydrocephalus by endoscopic cauterization of the choroid plexuses. J Neurosurg 33:1-18, 1970

31. Schmidt RH: Use of microvascular Doppler probe to avoid basilar artery injury during endoscopic third ventriculostomy. Technical note. J Neurosurg 90:156-159, 1999

32. Schroeder HWS, Warzok RW, Assaf JA, et al: Fatal subarachnoid haemorrhage after neuroendoscopic third ventriculostomy. Case report. J Neurosurg 90:153-155, 1999

33. Teo C, Jones R: Management of hydrocephalus by endoscopic third ventriculostomy in patients with myelomeningoceole. Pediatr Neurosurg 25:57-63, 1996

34. Teo C, Rahman S, Boop FA, et al: Complications of endoscopic neurosurgery. Childs Nerv Syst 12:248-253, 1996

35. Wilcock DJ, Jaspan T, Punt J: CSF flow through third ventriculostomy demonstrated with colour 
Doppler ultrasonography. Clin Radiol 51:127-129, 1996

36. Vandertop WP, Verdaasdonk RM, van Swol CFP: Laser-assisted neuroendoscopy using a neodymium-yttrium aluminum garnet or diode contact laser with pretreated fiber tips. J Neurosurg 88:82-92, 1998

37. Vloeberghs M, Cartmill M: Improved safety of neuroendoscopic third ventriculostomy by using an operative ultrasound probe. Technical note. Neurosurg Focus 6 (4):Article 11, 1999

38. Vries JK: An endoscopic technique for third ventriculostomy. Surg Neurol 9:165-168, 1978

Manuscript received March 8, 1999.

Accepted in final form March 16, 1999.

Address reprint requests to: Neil Buxton, F.R.C.S.(Ed), Department of Neurosurgery, University

Hospital, Nottingham, NG7 2UH, United Kingdom. 